\title{
Inhalt des achten Bandes
}

Filips von Zesen, Simson / eine Helden= und LiebesGeschicht $\ldots \ldots \ldots \ldots \ldots \ldots \ldots \ldots \ldots \ldots \ldots$. 1

Dem ... HERRN Heinrichen von Delwich ...... 5

Dem Deutsch $=$ und treu-gesinnetem Leser ....... 9

Das erste Buch ....................... 13

Das zweite Buch ....................... 59

Das dritte Buch ........................ 101

Das vierde Buch ...................... 147

Das fůnfte Buch ........................ 189

Das sechste Buch ...................... 239

Das siebende Buch .................... 277

Das achte Buch ....................... 319

Das neunde Buch ........................ 369

Das zehende Buch $\ldots \ldots \ldots \ldots \ldots \ldots \ldots \ldots \ldots, 421$

Die Fehler ....................... 485

Filips von Zesen Zugabe oder Anmårkungen ůber seinen Simson ............................. 487

Blatweiser ............................. 649

Nachwort des Herausgebers .................... 665 